\title{
SUPERFERRIC CORRECTION MAGNET TEST RESULTS
}

\author{
R. Rocha, J. Colvin, F. R. Huson, W. W. MacKay, Y. Miao \\ S. Pissanetzky, G. Shotzman, and J. Zeigler \\ Texas Accelerator Center ${ }^{\dagger}, 4802$ Research Forest Dr., \\ Bldg. 2, The Woodlands, TX 77381.
}

\section{Abstract}

The Texas Accelerator Center (TAC) has recently tested superferric quadrupole magnets which have shown improved performance characteristics over four previously tested quadrupoles. The quadrupole coils are wound from a single superconducting strand which is ultrasonically adhered to a substrate by Advanced Interconnection Technology (AIT). The magnets are constructed at the Texas Accelerator Center by rolling this coil/substrate package onto a mandrel. The coils are then surrounded and clamped by iron laminations to form a flux return path and provide a coil preload.

\section{INTRODUCTION}

The Superconducting Super Collider Laboratory (SSCL) is investigating three methods of fabricating correction magnets for the $\mathrm{SSC}$ correction elements. These three magnets types are: magnets made from randomwound coils, magnets made from direct-wound coils and magnets made from a jellyroll winding. Specifications for these magnets (see Table 1) include a maximum current of $100 \mathrm{~A}$ and field quality of $\pm 1 \%$. TAC is inves tigating the jellyroll method and has constructed nine quadrupoles thus far. Results for quadrupoles 1 - 4 were reported previously [1]. This report will provide results for recently tested quadrupoles.

Table 1

Specifications and estimated lengths for SSC correctors

\begin{tabular}{|c|c|c|c|c|c|}
\hline Function & Place & $\begin{array}{c}\text { BL } \\
\text { OIcm } \\
(\mathrm{Tm})\end{array}$ & $\begin{array}{c}\text { B } \\
(\mathrm{T})\end{array}$ & $\begin{array}{c}\text { Magnetic } \\
\text { Length } \\
(\mathrm{m})\end{array}$ & $\begin{array}{c}\text { Total } \\
\text { Length } \\
(\mathrm{m})\end{array}$ \\
\hline Dipole & F, D & 2.5 & 2.55 & 0.98 & 1.02 \\
\hline Quad & F, D, & 0.53 & 1.44 & 0.37 & 0.41 \\
\hline Sext & F & $\mathbf{0 . 1 0}$ & $\mathbf{0 . 6 1}$ & $\mathbf{0 . 1 6}$ & 0.25 \\
\hline Sext & C & 0.09 & $\mathbf{0 . 6 1}$ & 0.15 & 0.19 \\
\hline Sext & D & 0.16 & 0.61 & 0.26 & 0.38 \\
\hline Octup & F, D & 0.007 & 0.25 & 0.03 & 0.07 \\
\hline Octup & C & 0.016 & 0.25 & 0.06 & 0.10 \\
\hline Decap & F, D & 0.004 & 0.072 & 0.06 & 0.10 \\
\hline Decap & C & 0.009 & 0.072 & 0.13 & 0.17 \\
\hline
\end{tabular}

\section{MAGNET DESCRIPTION}

The jellyroll technique of correction magnet construction uses ultrasonic energy to accurately adhere a kapton insulated superconducting wire onto a flat substrate to form a coil. Two substrate materials have been used. Earlier in the test program, AIT used RC205, a proprietary material that incorporates a fiberglass mat with adhesive on both sides. Quadrupoles 6-9 have used Kapton as the substrate with a 0.005 " thick layer of XP-17 as the adhesive. The use of the latter substrate/adhesive combination correlates with improved magnet performance. The coil geometry is a two-layer racetrack wound onto a mandrel in a jellyroll manner. The resulting coil cross section is the desired quadrupole geometry. See Figures 1 and 2. This technique provides a high density conductor package and can easily be extended to the dipole and higher-order multipole magnets.

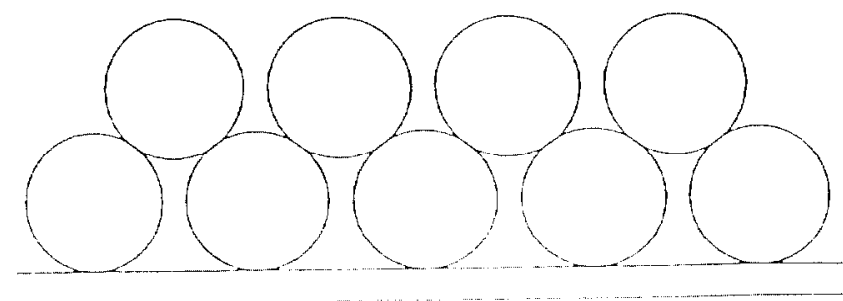

Figure 1. Cross section of two-layer racetrack winding.

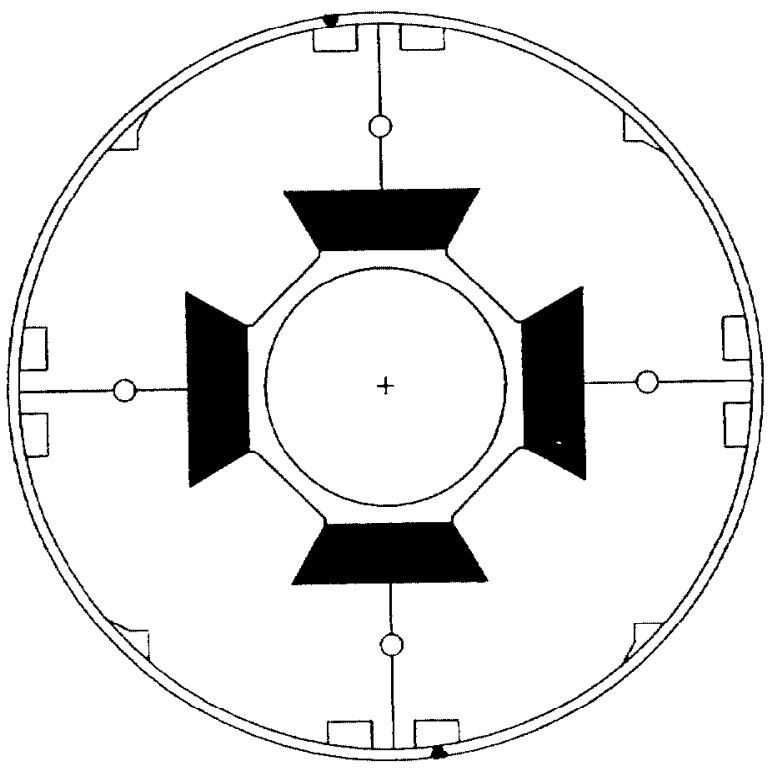

Figure 2. A cross sectional view of the superferric quadrupole correction magnet. The iron laminations provide a flux return path and a coil preload. The outer skin acts as a clamp. 


\section{EARLY RESULTS}

\section{Quadrupoles 1-7}

Thus far, nine quadrupoles have been constructed. Quadrupoles 1 - 4 had initial training quenches of 40 $60 \%$ of $I_{c}$ and required around $1-4$ training quenches to achieve $I_{c}$. During assembly of quadrupole 5 , the coil was irreparably damaged and therefore never tested. Quadrupoles 6 and 7 showed improved quench behavior [2]. Initial quenches occurred in the $65-85 \%$ of $I_{c}$ range with three to four quenches required to reach $I_{c}$. Field measurement for quadrupole 6 indicated good agreement between predicted and measured gradient strengths. Field analysis also reveals the harmonics to be within the design value of $\pm 1 \%$. Extensive measurements were taken in order to determine the hysteresis effects of the iron on field quality at low fields. See Figures 3 and 4 . The hysteresis effects were measured at well below the $1 \%$ level. Thermal cycle tests indicate that these magnets do not remember their previous training cycles. After quadrupoles 6 and 7 were tested, we decided to construct four more quadrupoles in order to qualify the jellyroll technique as a viable technology for SSC corrector magnets.

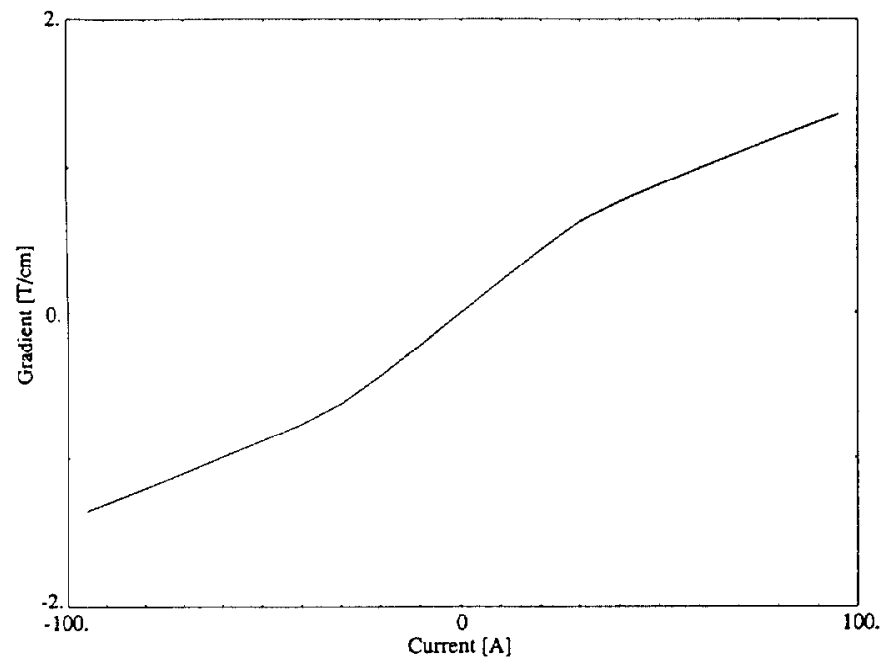

Figure 3. A complete hysteresis loop for quadrupole 6 .

\section{RECENT RESULTS}

\section{Quadrupoles 8 and 9}

Quadrupoles 8 and 9 had initial training quenches of $86 \mathrm{~A}$. The maximum operating current for this design is $90 \mathrm{~A}$ and the critical current is $100 \mathrm{~A}$. Quadrupoles 8 and 9 required 2 and 3 training quenches, respectively, before reaching critical current. After a training plateau was achieved, each magnet was cycled for 20 times to its critical current and then the procedure was repeated with a change in polarity. No additional training was required due to the polarity reversal. The test ramp rate is $0.1 \mathrm{~A} / \mathrm{s}$, but the magnets have been ramped occasionally as fast as $4 \mathrm{~A} / \mathrm{s}$. After the completion of these tests, the magnets were thermally cycled from $4.2 \mathrm{~K}$ to room temperature and back to $4.2 \mathrm{~K}$. These thermal cycles were to determine if the magnets remember their initial training cycles. See Figures 5 and 6 . With the exception of 3 thermal cycles, all subsequent first quenches occurred at or greater than $90 \mathrm{~A}$. The magnets usually achieved critical current within 2 training quenches. The reason for these additional training quenches is not understood. These two quadrupoles have been delivered to the SSCL where additional thermal cycles are planned.

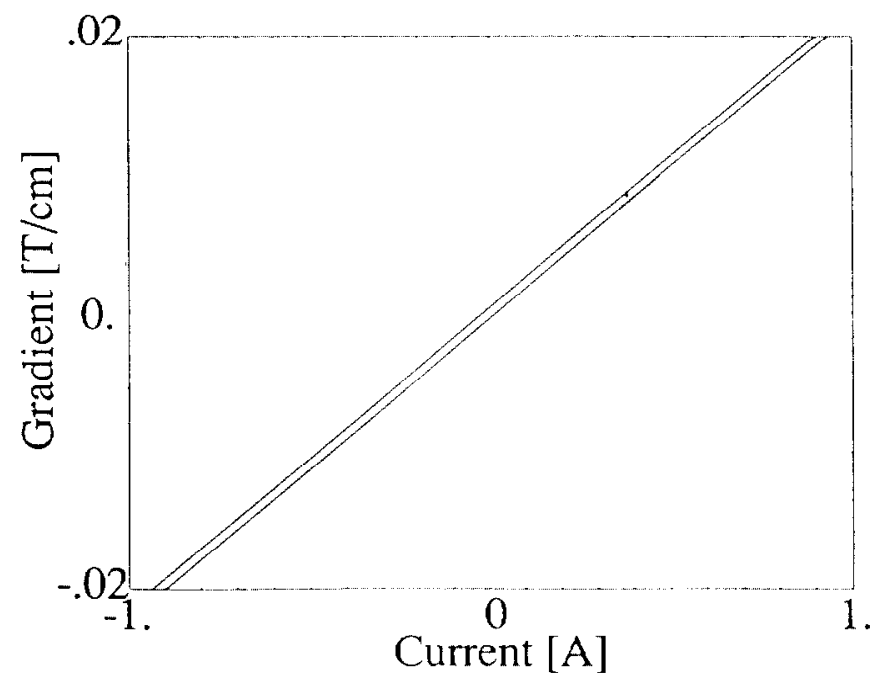

Figure 4. Hysteresis measurements at low fields.

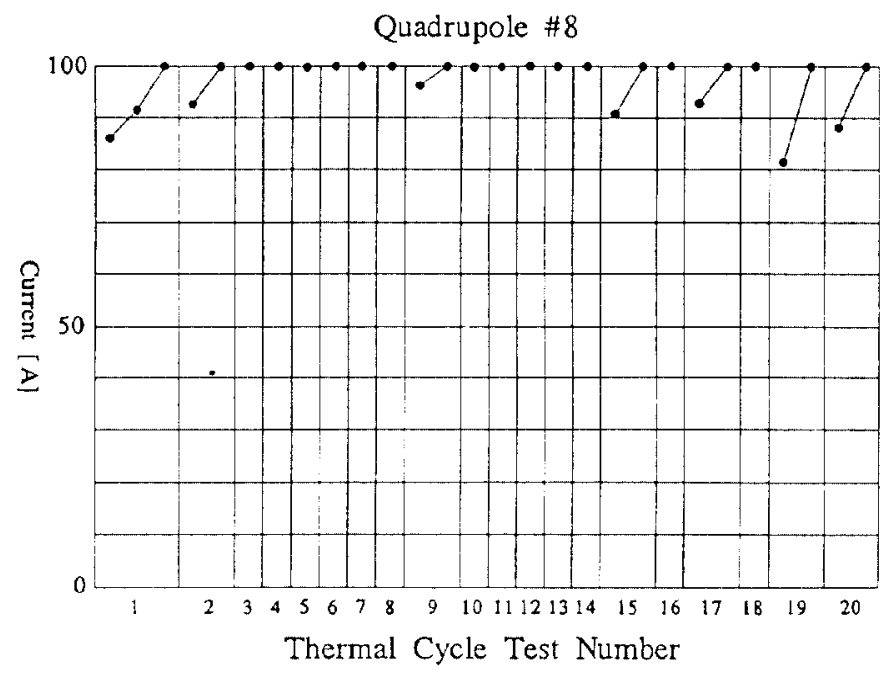

Figure 5. Quench Data for quadrupole 8. 


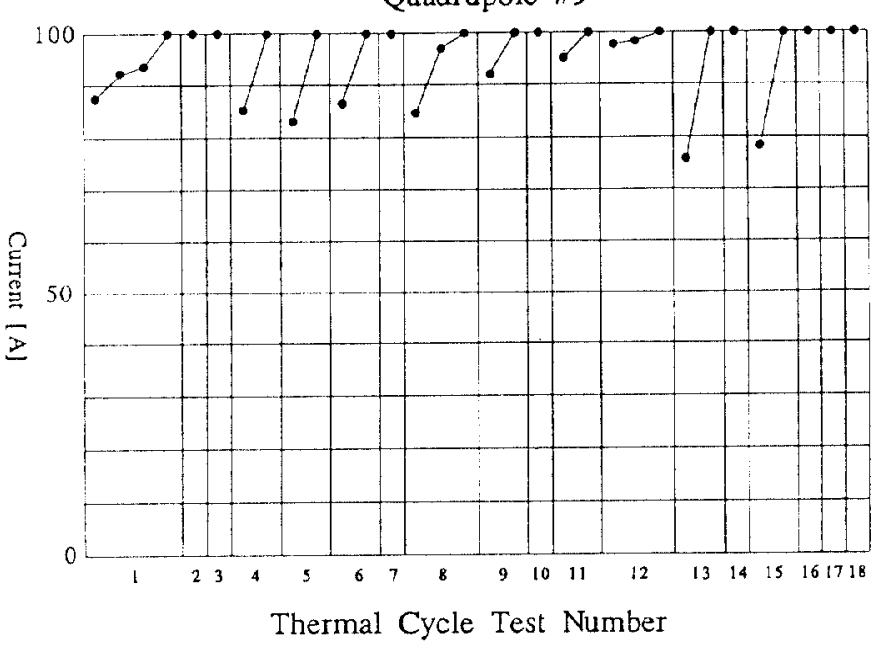

Figure 6. Quench data for quadrupole 9.

\section{FUTURE TESTS}

TAC is preparing to construct two more quadrupoles that will use a superconducting wire with a larger diameter. The change in wire diameter, from $0.013 \mathrm{in.}$ to 0.015 in., will not alter the coil package geometry but will allow the magnets to operate with a greater safety margin between maximum operating current and critical current. An additional test is planned for the next two quadrupoles. A measurement of the effects of synchrotron radiation loads will be made by attaching a nichrome heater onto the innerwall of the beamtube. This heater is designed to deposit $1.4 \mathrm{~W} / \mathrm{m}$ onto the beamtube wall. The effects of this heat load on the stability of these correctors will be determined. TAC has also designed a superferric correction dipole and sextupole. The dipole (see Figure 7) will be constructed next with the sextupole to follow.

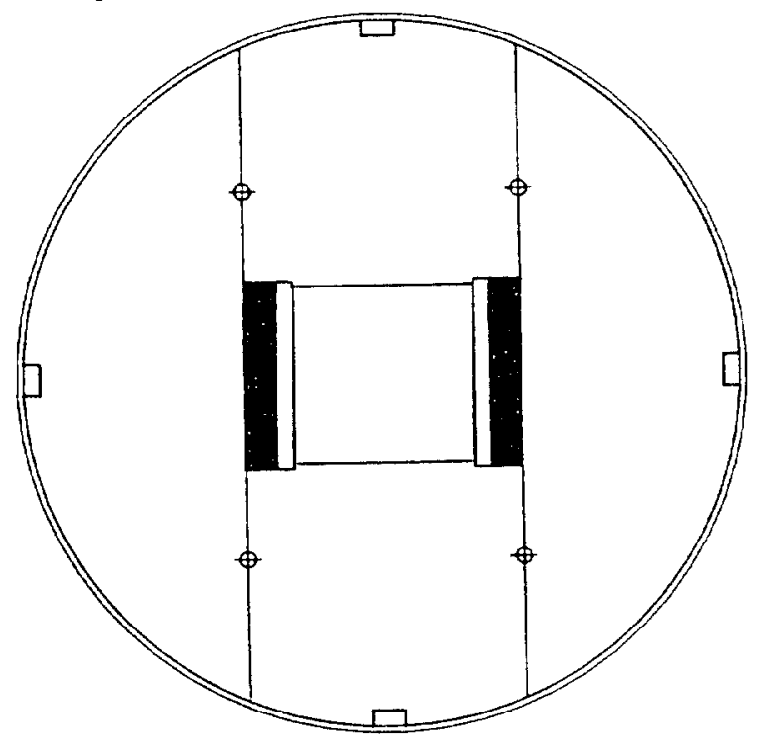

Figure 7. A cross sectional view of the superferric dipole correction magnet.
The successful tests of two superferric quadrupoles indicates that the jellyroll wound magnet is an efficient method of obtaining a high density coil package. The correctors are efficient in the use of superconductor, compact in size, and provide the necessary field quality. Construction has proven to be simple and can easily be automated. The transfer of this magnet technology to industry has begun.

\section{REFERENCES}

† TAC at HARC is a consortium of Rice University, Texas A\&M University, the University of Houston, the University of Texas, Prairie View A\&M University, Sam Houston State University, and the Baylor College of Medicine MR Center.

[1] J. Colvin, et. al., Superferric Correction Magnets for the SSC, IEEE Trans. on Magnetics, Vol. 27, No. 2, pp. 1892-1895, March 1991.

[2] J. Skaritka, et. al., Development of Superconducting Corrector Magnet Technology for Use in the SSC, Submitted for publication at the IISSC, Atlanta, GA March 1991. 